\title{
Climate change and the British Uplands: evidence for decision-making
}

\author{
Jo I. House ${ }^{1, *}$, Harriet G. Orr ${ }^{2}$, Joanna M. Clark ${ }^{3,4,5}$, Angela V. Gallego-Sala ${ }^{1,9}$, \\ Chris Freeman ${ }^{3}$, I. Colin Prentice ${ }^{1,4,6,7}$, Pete Smith ${ }^{8}$
}

\author{
${ }^{1}$ QUEST, Department of Earth Sciences, University of Bristol, Queen's Road, Bristol BS8 1HB, UK \\ ${ }^{2}$ Evidence Directorate, Environment Agency, Environment Centre Wales, Bangor LL57 2UW, UK \\ ${ }^{3}$ Wolfson Carbon Capture Laboratory, School of Biological Sciences, Bangor University, Environment Centre Wales, \\ Deiniol Road, Bangor, Gwynedd LL57 2UW, UK \\ ${ }^{4}$ Grantham Institute for Climate Change, Imperial College, South Kensington, London SW7 2AZ, UK \\ ${ }^{5}$ Walker Institute, Soils Research Centre, Department of Geography and Environmental Science, \\ School of Human and Environmental Sciences, University of Reading, Whiteknights, Reading RG6 6DW, UK \\ ${ }^{6}$ Department of Biological Sciences, Macquarie University, North Ryde, New South Wales 2109, Australia \\ ${ }^{7}$ Division of Biology, Imperial College, Silwood Park, Ascot SL5 7PY, UK \\ ${ }^{8}$ Institute of Biological and Environmental Sciences, School of Biological Sciences, University of Aberdeen, \\ 3 St Machar Drive, Aberdeen AB24 3UU, Scotland, UK
}

${ }^{9}$ Present address: Ecosystem Sciences, Division of Physical Geography and Ecosystems Analysis, University of Lund, Sölvegatan 12, 22362 Lund, Sweden

\begin{abstract}
We summarise the work of an interdisciplinary network set up to explore the impacts of climate change in the British Uplands. In this CR Special, the contributors present the state of knowledge and this introduction synthesises this knowledge and derives implications for decision makers. The Uplands are valued semi-natural habitats, providing ecosystem services that have historically been taken for granted. For example, peat soils, which are mostly found in the Uplands, contain around $50 \%$ of the terrestrial carbon in the UK. Land management continues to be a driver of ecosystem service delivery. Degraded and managed peatlands are subject to erosion and carbon loss with negative impacts on biodiversity, carbon storage and water quality. Climate change is already being experienced in British Uplands and is likely to exacerbate these pressures. Climate envelope models suggest as much as 50\% of British Uplands and peatlands will be exposed to climate stress by the end of the 21st century under low and high emissions scenarios. However, process-based models of the response of organic soils to this climate stress do not give a consistent indication of what this will mean for soil carbon: results range from a very slight increase in uptake, through a clear decline, to a net carbon loss. Preserving existing peat stocks is an important climate mitigation strategy, even if new peat stops forming. Preserving upland vegetation cover is a key win-win management strategy that will reduce erosion and loss of soil carbon, and protect a variety of services such as the continued delivery of a high quality water resource.
\end{abstract}

KEY WORDS: British Uplands $\cdot$ Climate change $\cdot$ Peat $\cdot$ Soil carbon $\cdot$ Water quality $\cdot$ Ecosystem service Management

Resale or republication not permitted without written consent of the publisher

\section{IMPORTANCE OF THE BRITISH UPLANDS}

The British Uplands are greatly valued as a highly distinctive type of semi-natural habitat, including many areas with protective designations such as Sites of Special Scientific Interest (SSSIs), National
Parks, Nature Reserves and Areas of Outstanding Natural Beauty. The Uplands are important providers of ecosystem services which, until recently, have largely been taken for granted (Maltby 2010, this Special); they also include blanket bogs - a globally rare habitat. 
The Uplands include extensive areas of organic soils, such as blanket peat, which provide several important services. Specialised peatland plant biodiversity includes many species of bog mosses (Sphagnum), which build and maintain peat. Peat, in turn, provides an unusually high density of carbon (C) storage. Where peat is forming, it takes up carbon from the atmosphere and acts as a long-term carbon sink. More important from a contemporary carbon cycle perspective is the amount of carbon that has accumulated in peat over many millennia. Peatlands store about $50 \%$ of the terrestrial carbon in the UK, about 2300 Mt C (Billett et al. 2010, this Special). Preserving existing peat stocks is an important climate mitigation strategy, even if new peat were to stop forming. We calculate that a loss of just $12 \%$ of UK peat carbon would be equivalent in climatic effect to the total annual UK emissions of greenhouse gases from the burning of fossil fuels.

Peatlands provide a regulating function by absorbing and retaining atmospheric pollutants including sulphur, nitrogen and heavy metals which would otherwise be degrading water quality in downstream areas, although this can cause damage to the peatland ecosystem itself. About $70 \%$ of the UK's drinking water supply comes from surface waters, mainly from the Uplands. Extensive erosion of peat leads to losses of particulate and dissolved organic carbon (POC, DOC) and fine sediments, and could potentially release the legacy of heavy metals and other pollutants built up in the peat since the Industrial Revolution. Declining acid deposition, increased temperatures, atmospheric carbon dioxide $\left(\mathrm{CO}_{2}\right)$ and land management could increase the amount of DOC loss from peat to surface waters (Freeman et al. 2001, Freeman et al. 2004, Monteith et al. 2007, Clark et al. 2010a, Yallop et al. 2010, this Special). Silting of reservoirs and changes in water quality and water colour would lead to rising water treatment costs that could result in some sites no longer being cost-effective for water supply. The hydrological functioning of peat soils can influence peak river flows and flooding, although very high rainfall quickly leads to saturation and increased run-off (Bonn et al. 2009a, Holden 2009). Further research is needed to quantify the impact of recent drain blocking on peak flows and runoff changes. In general, environmental managers need a more in-depth understanding of the upland environment to help stakeholders maximise benefits (Orr et al. 2008).

We are already witnessing the impacts of humaninduced environmental change in the Uplands. Some areas are experiencing serious degradation through over-grazing, draining, burning, planting with conifers, and in situ effects of atmospheric pollution (Holden et al. 2007, Orr et al. 2008, Bonn et al. 2009a). Interactions between growing pressures on the land and climate change could further threaten the delivery of vital services from these ecosystems.

This CR Special arises from an interdisciplinary Working Group and national network set up to understand the potential impacts of climate change in the British Uplands, and the implications of these impacts for ecosystem services and management. The network includes scientists, practitioners, and representatives of agencies and industries. Funding priority was given to work that used climate projections to identify areas most at risk of change, and the implications of this change for peat formation and persistence (House et al. 2010, Clark et al. 2010b,c,d, this Special, Gallego-Sala et al. 2010, this Special). Ongoing work by network partners also included in this Special gives a broad picture of upland peat condition (Billett et al. 2010); drivers of change-including burning (Yallop et al. 2010), gully erosion (Evans \& Lindsay 2010, this Special) and climate change (Burt \& Holden 2010, Coll et al. 2010, both this Special); model studies of change due to different drivers (Heinemeyer et al. 2010, Smart et al. 2010, Smith et al. 2010a,b, all this Special); implications of climate change for upland birds (Pearce-Higgins 2010, this Special) and wildfire (Albertson et al. 2010, this Special); and application of the ecosystem services approach to uplands (Maltby 2010, Cornell 2010, this Special). In this introduction, we bring together the evidence presented and evaluate the implications for managing upland ecosystem services under a changing climate.

\section{CONDITION OF THE UPLANDS, AND DRIVERS OF CHANGE}

Although the term 'uplands' is widely used in Great Britain (GB), there are many different definitions for upland areas, variously estimated to include 16.7 to $42.1 \%$ of the land surface of GB (Clark et al. 2010b). The Uplands are represented by some of the most economically deprived agricultural areas, defined by the European Union as Severely Disadvantaged Areas (SDAs). The British Uplands are subject to many drivers of change. Large areas are actively managed today including the widespread use of drainage, prescribed fire, peat extraction, grazing, fertilisation and liming (Holden et al. 2007) and more recently for wind farming. Vegetation type and productivity are significantly affected, as is soil condition.

Much of the peat soil in Britain is found in upland areas, and the Scottish Uplands include extensive areas of peat. Although carbon sequestration is not the only important indicator of peatland condition and services, it is a good indicator of the function of peatlands, the change in drivers and services, and the state of the environment generally. Therefore, several of the studies in 
this Special focused on upland peats and carbon. British peatlands have been accumulating carbon for $\sim 8000 \mathrm{yr}$ because of the slow decomposition of plant material in anoxic and acidic conditions in wet soil due to climatic conditions since the end of the last ice age, especially during the latter half of the Holocene (Charman 2002). The long-term viability of peatlands is based upon their ability to continue to take up more carbon from the atmosphere (via photosynthesis) than they lose through export pathways (plant and soil respiration, POC loss through erosion and DOC loss in water outflows). Cultivated peatlands can lose 3 to $10 \mathrm{t} \mathrm{C} \mathrm{ha}^{-1} \mathrm{yr}^{-1}$ (Nykänen et al.1995, Maljanen et al. 2001, 2004, Lohila et al. 2004). Eroding peatlands in the UK are losing up to $1 \mathrm{t} \mathrm{C} \mathrm{ha-1}$ $\mathrm{yr}^{-1}$ (Evans et al. 2006). UK peatlands have been significantly impacted by changes in reactive nitrogen $(\mathrm{N})$ and sulphur (S) deposition (e.g. Evans et al. 2006, Moors for the Future 2007), with recent decreases in acid deposition having led to increased DOC losses (e.g. Evans et al. 2006, Monteith et al. 2007). We do not fully understand what the impact of these changes in the chemical environment of peatlands has been on long-term carbon turnover. In addition, peatlands may already be experiencing the impacts of recent climate change.

Billett et al. (2010) review the current state of knowledge on the carbon balance of UK peatlands. The few data that are available show that some UK peatland areas are continuing to act as carbon sinks, although the sink strength has declined over the last $100 \mathrm{yr}$. Detailed measurements from 2 sites show accumulation rates of -56 to $-72 \mathrm{~g} \mathrm{C} \mathrm{m}^{-2} \mathrm{yr}^{-1}$ (negative fluxes represent net uptake from the atmosphere). There is high interannual variability in carbon uptake, indicating the sensitivity of peatland carbon accumulation to climate. Auchencorth Moss in Scotland varied from being a small source of $\mathrm{CO}_{2}$ in $2003\left(+20 \mathrm{~g} \mathrm{C} \mathrm{m}^{-2} \mathrm{yr}^{-1}\right)$ to a significant sink in $2008\left(-136 \mathrm{~g} \mathrm{C} \mathrm{m}^{-2} \mathrm{yr}^{-1}\right)$ (Dinsmore et al. 2010). Historical rates of carbon accumulation measured using peat cores provide a long-term context for present-day measurements. Carbon accumulation rates over the last $150 \mathrm{yr}$ have ranged from -35 to $-209 \mathrm{~g} \mathrm{C} \mathrm{m}^{-2} \mathrm{yr}^{-1}$ (Billett et al. 2010).

The loss of POC into rivers in eroding systems may be higher than previously thought (Billett et al. 2010). Evans \& Lindsay (2010) highlight the POC losses from gully erosion and decomposition of surface peats. The upland blanket bogs of the UK have suffered severe erosion due to land use and extensive drainage in recent centuries and in some regions they are widely dissected by gully systems. One English site has shifted from being a net sink of carbon $\left(-20.3 \mathrm{~g} \mathrm{C} \mathrm{m}^{-2} \mathrm{yr}^{-1}\right)$ to a net source $\left(29.4 \mathrm{~g} \mathrm{C} \mathrm{m}^{-2} \mathrm{yr}^{-1}\right)$ due to gully erosion. Reduced carbon fixation due to vegetation loss and ongoing erosional loss of POC were the major causes of carbon loss but are poten- tially reversible with intervention (e.g. revegetation, gully blocking).

Billett et al. (2010) also summarise evidence for increases in DOC losses from peatlands. Records at several sites over the period 1988-2003 show $91 \%$ increases in DOC concentrations observed in drainage waters from upland catchments with organic soils (Evans et al. 2005). Isotope studies suggest that the majority of this additional DOC is derived from recently fixed plant material rather than from older peat (Palmer et al. 2001, Evans et al. 2007), although some older carbon is being released in peatland streams; a part of this old carbon may have remained immobile for hundreds or even thousands of years (Billett et al. 2007). Yallop et al. (2010) looked specifically at DOC exported from peatlands and other organic soils, as concentrations at 3 sites in the South Pennines had doubled since 1980. They argued that the main driver at these sites was the extensive use of burning for grouse moor management. Yallop et al. (2010) found that declining sulphur deposition was inversely related to DOC export, but they were not able to explain the variation in DOC trends between the 3 sites that had experienced similar deposition levels. Although evidence suggests a link between declining sulphur deposition and increasing DOC concentrations across areas of Europe and North America experiencing acid deposition (e.g. Monteith et al. 2007), the study by Yallop et al. (2010) highlights how specific catchment characteristics and management practice can also influence DOC trends locally, over and above background trends driven by large-scale regional changes (Clark et al. 2010a).

Yallop et al. (2010) found that burning increases DOC fluxes, but this does not necessarily indicate changes in the overall carbon balance. For example, Ward et al. (2007) found that both peatland burning and grazing increased $\mathrm{CO}_{2}$ fluxes, strongly related to the change in vegetation that occurred (from shrubs to graminoids). For burning, the increase in photosynthetic carbon uptake (by as much as $40 \%$ ) was greater than the increase in the respiration leading to an overall net increase in gaseous $\mathrm{CO}_{2}$ uptake. However, burning reduces carbon stocks in the surface peat. This example highlights the importance of plant-soil interactions as key regulators of peatland ecosystems, with changes in plant composition and productivity playing an important role.

The studies above (Ward et al. 2007, Billett et al. 2010, Yallop et al. 2010) highlight the importance of considering all aspects of the total ecosystem carbon balance when estimating the long-term implications for carbon storage. Using the rates of current carbon loss in 2 degraded peatlands, the time taken to release all the soil organic carbon would be $4300 \mathrm{yr}$ for a site in NE Scotland (aquatic loss only) and $1150 \mathrm{yr}$ for the Bleaklow Plateau (POC losses only) (Billett et al. 2006). Therefore, even considering additional loss that may 
result from future climate change, there is likely to be a centennial to millennial scale period for managing declining peatlands. Estimation of the magnitude of various biogeochemical flux pathways in peatlands, their changes, and attribution of changes to specific environmental causes, constitute an area of science that is still in the initial stages of development, and there are important gaps and uncertainties (Billett et al. 2010). A finding common to several studies in this Special was the high spatial variability of fluxes, with local plant cover, topography and management all influential.

\section{QUANTIFYING CLIMATE CHANGE FOR IMPACT ASSESSMENTS}

Direct observations of recent climate (Burt \& Holden 2010, Coll et al. 2010) suggest upland areas are already experiencing change, and that this change is greater than in lowland systems. Burt \& Holden (2010) found that over the period 1961-2000 upland weather stations showed a rise in mean temperature that was stronger in winter than in summer, with minimum temperature rising more than maximum temperature, whereas in the lowlands the changes were similar between minima and maxima. Most (but not all) upland stations showed significant increases in rainfall totals in winter that were greater than those experienced in the nearby lowlands. The changes observed also suggest an extending growing season in some upland areas. Increased rainfall and temperature may be responsible for some of the increase in carbon flux described in Billett et al. (2010). Higher run off at high elevations in winter when bare peat is loosened by freeze-thaw activity may increase POC loss, although this effect could be countered by warmer conditions.

Differences between upland and lowland weather stations observed by Burt \& Holden (2010) and Coll et al. (2010) suggest lowland data cannot be used to infer change in the Uplands (Malby et al. 2007). In the UK, only $4 \%$ of temperature stations that have ever been operational are located above $300 \mathrm{~m}$ and yet around onethird of the UK's land surface is higher than $300 \mathrm{~m}$. Spatial heterogeneity between upland weather stations is also significant due to topography, the effects of regional circulation patterns, and feedbacks related to snow and ice cover in zones with seasonal mean temperature close to $0^{\circ} \mathrm{C}$ (Manley 1952, Burt \& Holden 2010). Seasonal and spatial climate heterogeneity due to scaledependent local controls is not fully captured in the present generation of Global Climate Models (GCMs) and Regional Climate Models (RCMs) due to the relatively course resolution of model grids. Coll et al. (2010) propose a methodology of combining information from weather station data on the gradients of temperature change between upland and lowland areas (lapse rate) with RCM outputs, to capture the scale of change more likely to be experienced in upland environments.

Characterising climate in the Uplands is critical to assessing changing climate stress. By combining key climatic variables (rainfall, temperature, etc.), simple climatic indices can be produced to define the limits of upland environments, and these can be used to look at exposure to climate stress. Clark et al. (2010b) found indices that combined growing season length (measured as annual accumulated temperature) with the amount of rainfall or number of raindays provided the most robust delineation of mapped 'upland areas' using the EU's SDA classification. Climate projections from the UK Climate Impacts Program (UKCIP02, Hulme et al. 2002) based on IPCC projections (Intergovernmental Panel on Climate Change, IPCC 2000) generally indicate warmer temperatures with drier summers and wetter winters, but little change in total annual rainfall. Using the climate indices with projections under high (A1F1) and low (B2) emissions scenarios, by 2080 the areas projected to experience an 'upland climate' declined by 13 to $51 \%$ for the low emissions scenario and 24 to $84 \%$ for the high emissions scenario. 'Upland climate areas' retreated towards cooler higher altitudes and wetter western areas with low altitude areas in the east of Great Britain most exposed to a change in climate to one untypical of uplands (Clark et al. 2010b).

What will climate change mean for upland ecosystems? Effects on upland peats are dealt with in the next section. For the Peak District, Albertson et al. (2010, this Special) found that for UKCIP02 low and high emissions scenarios (A1F1 and B1) there was an increase in wildfire risk with temperature, particularly in summer months. The risk rises slowly at first, and increases substantially after 2070. Warmer and drier conditions would also affect food supply for many animal species. For example, Pearce-Higgins (2010) carried out an extensive literature review to identify the sensitivity of upland birds diet to climate. Several key insectivorous prey species were found to decline with summer drought conditions, the contribution of these species to bird diet provides an index of climate sensitivity. There was a significant correlation between this index and recent trends in upland bird populations. The author suggests that since these prey species are drought sensitive, grip (drain) blocking may mitigate future climate effects.

\section{MODELLING CHANGE IN UPLAND PEAT ECOSYSTEMS}

In the British Uplands, it is the unusually cool and wet maritime environment that supports the develop- 
ment of rare blanket bogs in poorly drained areas and accumulation of carbon in unsaturated organic soils in freely draining areas. The geographical extent of 'rainfed' blanket peatlands is sensitive to climate, as it is this climate that ultimately allows persistence of saturated conditions which determines plant growth and longer-term soil formation. In a warming climate, bog mosses and other peat-forming species may no longer thrive, making the peat mass more vulnerable and unstable. Warmer and/or drier conditions could also encourage the growth of vascular plants, which have higher evapotranspiration rates and are able to lower the water table and therefore increase carbon mineralisation and nutrient release: this in turn favours the dominance of these species, in a positive feedback loop. Exploring such complex feedbacks would require dynamic process-based models that interactively couple organic soils and vegetation dynamics. Currently, there are no such fully coupled models for vegetation on organic soils; most vegetation dynamic models only deal with vegetation on mineral soils. However, there are various models available that can be used to give an indication of the vulnerability of peatlands to climate change. Existing models include bioclimatic envelope models (e.g. Clark et al. 2010c, Gallego-Sala et al. 2010, Smart et al. 2010) and models that specifically represent processes in organic soils and soilvegetation linkages (Heinemeyer et al. 2010, Smith et al. 2010a,b).

Bioclimatic Envelope Models (BECMs) or niche models are widely used to study the current distribution of species and to project changes under future climate scenarios. These models derive a statistical relationship between the observed current distribution and current climatic variables, defining the 'environmental space' associated with a particular habitat or species. This is similar to the climatic indices used to define upland areas (Clark et al. 2010b). Clark et al. (2010c) looked at the climate related to the distribution of blanket peat with 8 BECMs. Models that included measures of both hydrological conditions and maximum temperature provided a better fit to the current mapped peat area. The shrinking bioclimatic envelope suggests that $>50 \%$ of GB peat will be exposed to change by 2050 ; this is the case for low and high greenhouse gas emission scenarios (see Clark et al. 2010c, their Fig. 6). Southern and eastern regions (Northumbria, North York Moors, Peak District, South West) were identified as being more exposed to projected changes in climate than higher-altitude western and northern areas. Note that the maps show a change in the bioclimatic space associated with peat, not a change in the area of peat itself.

Gallego-Sala et al. (2010) used a process-inspired BECM (PeatStash) to explore blanket bog ecosystem distribution. In this model, the bioclimatic variables were chosen because of their relationship to the physiological conditions under which peatland ecosystems can form (Pearson \& Dawson 2003). The model's parameters were calibrated, within pre-defined bounds, so as to optimally delineate the spatial distribution of blanket bogs globally. It was then applied to the British Isles and was able to predict the distribution of blanket bogs as well as the best BCEMs from Clark et al. (2010c), which had been calibrated based on a sub-set of the UK data. For the period 2071-2100, under the UKCIP02 high emissions scenario, application of this model indicated a decline in the areal extent of actively growing blanket bogs by $84 \%$ compared to contemporary conditions. Only parts of western Scotland remained inside the climate envelope for blanket bogs. UKCIP02 uses the results from the Hadley Centre GCM, but GCMs can give quite different projections for the same climate scenario, particularly regarding precipitation. Projections for the same scenarios from 7 GCMs resulted in different magnitudes, but similar spatial patterns of change, with the UKCIP projection in the middle of the range (Gallego-Sala et al. 2010).

Smart et al. (2010) used 2 statistical techniques to construct BECMs for models of the distribution of Sphagnum species in Britain. Future projections of changes in the distribution of these species considered nitrogen and sulphur deposition scenarios as well as climate change. Acid deposition has been associated with decline in Sphagnum cover and peatland degradation. The South West, Brecon Beacons and western Lake District were identified as areas most vulnerable to the combination of these drivers.

Recognized limitations of bioclimatic models derive from their static correlative nature, however the models are an easy tool to use (Clark et al. 2010c, GallegoSala et al. 2010, Smart et al. 2010). A fundamental issue for the application of BCEMs (including processinspired BCEMs such as those of Gallego-Sala et al. 2010) in the context of vulnerability analysis is that they can only give information about exposure to climate stress, not sensitivity. In other words, these models do not provide any information about what could happen to the carbon stored in peatlands due to changes in the water balance and feedbacks between soils and vegetation once the climate becomes 'unsuitable'. Tackling this issue requires models that capture these processes explicitly. For example, Heinemeyer et al. (2010) developed the MILLENNIA peat cohort model to explore change over thousands of years, enabling benchmarking with peat age, paleo climate and vegetation data. The model explicitly represents the effects of water table depth and litter quality on decomposition rates. 
Another dynamic process model, ECOSSE developed by Smith et al. (2010a) can simulate soil carbon stocks across a range of organic soil types (including blanket bog) using minimal data inputs. Smith et al. (2010b) used this model to examine changes in soil carbon content due to land-use change in Scotland during 1950-2009. They show that losses from carbon-rich organic soils, were $63 \mathrm{Mt} \mathrm{C}$ over this period, greater than the $35 \mathrm{Mt} \mathrm{C}$ from mineral soils, and that for carbon-rich soils, $64 \%$ of the total soil carbon loss occurred in the last $10 \mathrm{yr}$. Mitigation options through vegetation management were considered. Cessation of conversion of semi-natural land to grassland and conversion of grassland back to semi-natural land together were found to be capable of stopping the continuing net carbon loss from Scottish soils.

To gain insight into how outputs from bioclimatic models and dynamic process-based models compare as estimates of the climate vulnerability of peat, a model inter-comparison was carried out at 4 sites across the UK, pooling data and expertise across the project network (Clark et al. 2010d). Using the ensemble of 11 climate model projections underpinning the UKCP09 medium emission scenario (A1B), the 9 bioclimatic envelope models from Clark et al. (2010c) and Gallego-Sala et al. (2010) showed a similar decline in the climate associated with blanket peat at the 4 study sites, i.e. predictions of blanket peat 'presence' switched to predictions of blanket peat 'absence' for most models and projections (meaning that the climate shifts towards conditions that could be interpreted as no longer allowing active peat growth), although for each site some models and projections still predicted 'presence' by the end of the century. In other words, there was general agreement between the bioclimatic models about increasing exposure to climate stress. But can this be used as an indicator of what will actually happen to the peat? This might be so if the process models showed a similar response of the peat to this climate stress.

In fact, the dynamic process-based models showed differing predictions of what might happen to the actual net soil carbon flux between the atmosphere and the peat (Clark et al. 2010d). ECOSSE (Smith et al. 2010a,b) predicted a strong decline in net carbon uptake and a shift of the peatlands from being a carbon sink to source by the end of this century. The Durham Carbon Model (Worrall et al. 2009) predicted a smaller decline in carbon uptake by the peatlands, and did not indicate a shift to a carbon source. MILLENNIA (Heinemeyer et al. 2010) predicted a slight increase in carbon uptake by the peatlands. The variation between the models can be attributed to the use of different approaches to modelling soil organic matter pools, decomposition and soil-vegetation feedbacks.
For example, feedbacks between temperature, lowering water table, vegetation change and litter quality in MILENENIA led to changes in decomposition, but the predominant effect was the increase in plant carbon accumulation. This reinforces the significance of plantsoil-water relationships and feedbacks and the need to improve our understanding of whole ecosystem carbon dynamics (Billett et al. 2010). Enhanced data collection, in particular monitoring the response of extant peatlands to current climate change is essential if modelling and future projections are to be put on a firmer footing.

\section{IMPLICATIONS FOR DECISION MAKERS}

The results presented in this Special show that many areas of the Uplands are likely to experience a change in climate away from that typically associated with upland environments, peat growth and distribution of specific species important to the functioning of blanket bogs such as Sphagnum spp. Current pressures due to land use and management are likely to be exacerbated and some new pressures brought to bear. The more extreme projections bring a risk of peat instability with the potential for rapid mass erosion, loss of carbon, loss of biodiversity and change in water quality. Here we describe some of the specific implications for peatland management that arise from the information presented in this Special, and briefly discuss options and approaches for managing change.

\subsection{Effects of climate change on key services}

Vegetation type and biodiversity. Vegetation is likely to change to a composition more characteristic of drier conditions, perhaps with more grasses, some of which may still grow peat (Heinemeyer et al. 2010). These areas may become more suitable for agriculture as the climate becomes warmer, which would increase pressures from land management, although this has not been assessed in this Special. Excessive burning, overgrazing and drainage can lead to loss of vegetation cover and rapid erosion of peat, sometimes resulting in deep and extensive gully erosion (Billett et al. 2010, Evans \& Lindsay 2010, Smith et al. 2010b, Yallop et al. 2010). Climate change may exacerbate erosion where vegetation cover is already reduced e.g. by lowering the water table, which may be unfavourable for the growth of Sphagnum spp. Climate change is likely to lead to a decline in extent of rare blanket bog habitats (Clark et al. 2010c, Gallego-Sala et al. 2010, Smart et al. 2010) with impacts on their unique biodiversity. A 
change in upland climate is likely to affect the availability of prey for certain bird species (Pearce-Higgins 2010).

Water quality. Water quality will decline where peat erosion leads to lowering water tables and thus increasing export of particulate and dissolved organic carbon (POC, DOC), fine sediments and heavy metals (Evans et al. 2006). Potential changes in runoff are not well understood although greater flooding from winter rain is likely.

Wildfire. Wildfire risk and management has not traditionally been part of the upland scene in the UK but has been a problem in some very dry periods and where visitor numbers are high (McMorrow et al. 2009). Climate change is likely to increase the risk of summer wildfires and new measures will be needed to prevent damage to water supplies and peat carbon stores; options may include controlled burning, grazing or mowing to remove fuel (Albertson et al. 2010).

Carbon uptake and storage. This is a major ecosystem service of British peatlands and could play an important role in future national and international climate change mitigation policy. Our current knowledge suggests that British peatlands continue to operate as long-term sinks for carbon unless they are affected by intensive management. Land management, gully erosion and burning all lead to loss of carbon, but we are unable to quantify the resulting flux changes at a national scale. Models cannot yet give consistent indications of climate change driven carbon flux in the UK (Clark et al. 2010d). It is therefore difficult to provide robust evidence on climate impacts on peatlands to inform climate policy and peatland management. On balance we consider it likely that carbon uptake in peat surviving in areas no longer within the climate envelope will decline, but we cannot say at what rate this will occur, and we are less certain what will happen to the carbon store (Clark et al. 2010d).

Understanding the interactions between local and regional pressures on the contemporary carbon balance is incomplete. Attempts to quantify the carbon budget of UK peatlands and role of different drivers are limited by lack of long-term data sets at a sufficient number of sites to capture the variability of environments and drivers (Billett et al. 2010). However, degraded peatlands are likely to lose carbon more rapidly. Whilst the timescale of peat loss will at least be hundreds of years, negative impacts such as deteriorating water quality are likely to be observed on shorter time scales. Oxidation of peat due to drying will release $\mathrm{CO}_{2}$, but this effect will be offset to some (unquantified) extent by reduced emission of the greenhouse gases and nitrous oxide which are produced under suboxic or anoxic conditions.

\subsection{Management options}

Despite the many uncertainties, we can identify clear strategies to support a variety of peatland services. Peat in good condition is far more likely to be resilient to environmental changes including the impacts of a warming climate. While some blanket peatlands may lose the ability to actively fix carbon, careful management can protect the huge carbon stores and continue to provide other services, such as soil erosion protection, wildlife habitat, and grazing, as well as opportunities for recreation and enjoyment. Current restoration programmes (including re-vegetation of bare peat) have demonstrated success after only 4 yr (Wilson et al. 2010). Restoring carbon rich soils to their original vegetation cover is likely to reduce carbon loss (Smith et al. 2010b). Currently one of the most widespread peatland management interventions in the UK is drain or 'grip' blocking (Holden et al. 2007); this aims to reverse the drainage process by restoring the water table to natural levels, with positive effects for biodiversity, habitat, water, carbon storage and amenity value. Grip blocking can capture sediment and thereby reduce sediment loads in streams, which may reduce the negative effects such sediment has on fish breeding grounds. Blocking gullies and drains can also help prevent bare peat from developing, thereby supporting carbon storage and uptake (Evans \& Lindsay 2010).

\subsection{Ecosystems approach}

Reducing the risk of direct and indirect damage to upland ecosystems has considerable cost implications. We can enhance the resilience of existing peatlands through careful vegetation management, and thereby reduce the risk of losing valuable services. The resources to do so are not currently available. But recognition of the importance of ecosystem services that are not valued within conventional economic markets is gaining ground amongst policy makers and regulators. Water supply management in the UK has seen a small but significant change in emphasis in recent years, with OFWAT (the England and Wales water industry regulator) approving the spending by water companies to manage land for water quality rather than relying on traditional 'end of pipe solutions'. The Sustainable Catchment Management Programme (SCaMP) project in North West England is a good example. Such endeavours have hinged on the need to obtain evidence that new approaches to land and water management will indeed provide additional benefits and cost savings. There have been several demands recently for improved understanding and assessment of the source/ sink status of UK peatlands to inform policy, as envi- 
ronmental stewardship moves from a single resource approach to land (focused on exploitation for food production) to a more holistic ecosystem services approach (Everard et al. 2009).

The concept of ecosystem services may help forge an integration of natural science, economics and social science in this field. The urge to tackle unsustainable economic drivers of environmental degradation has led to a remarkably rapid penetration of the concept in research and policy agendas (Cornell 2010). However, as Cornell explains, this approach (for which expectations are high) is not without difficulties. One of the biggest of these is simply the paucity of underpinning evidence to support the wider application of this concept. Not all ecosystem services can be delivered everywhere, and attempts to map ecosystem services have shown that data availability currently limits the identification of regulating services (Bonn et al. 2009b). For example, assessing carbon and water storage requires more information on peat depth. There is also a risk that placing a value on a particular ecosystem service, such as carbon storage, can disconnect from the function of the ecosystem generating that service, which relies on the health of the ecosystem as a whole (Cornell 2010). Hopes for an ecosystems approach to resolve often conflicting land uses through a more integrated land management policy depend very much on getting over the very large hurdle of working across disciplines to develop an integrated evidence base, which in turn requires that we surmount the cultural obstacles that continue to stand in the way of effective collaboration across disciplines (Maltby 2010).

The delivery of societal benefits - which previously may have been undetected, undervalued or simply taken for granted - is also difficult, due to conflicting uses and impacts (Maltby 2010). A recent study applying an ecosystems approach identified a greater number of conflicts (62) compared to synergies (49) in an English Upland peat region (the Peak District) (Bonn et al. 2009b). Some win-win options can be identified. Pearce-Higgins (2010) presents an example: although insectivorous food supplies for upland birds are likely to decline due to climate change, restoration of peatland water tables should promote new food supplies while also providing other water quality and biodiversity benefits.

\section{CONCLUDING REMARKS}

This collective body of work has provided a consensual understanding of the condition of and pressures on GB Uplands, particularly upland peats, the state of the knowledge and uncertainty. Upland peats in GB are already experiencing degradation and loss of car- bon, but this is mainly due to land use practices, while the pressures of acid pollution are declining (Billett et al. 2010, Lindsay \& Evans 2010, Smith et al. 2010b, Yallop et al. 2010). Some areas are probably already experiencing impacts of climate change (Burt \& Holden 2010, Coll et al. 2010). This pressure will certainly increase. We can give an indication of the vulnerability of peatlands to climate change. We have been able to identify and quantify the exposure of upland areas and blanket peats to climate change, but we have much less knowledge about the dynamic response of their vegetation and carbon balance. It is likely that large geographic areas of the British Uplands will no longer experience a climate that is typical of current upland environments (Clark et al. 2010b), or that currently supports peat growth and the persistence of Sphagnum species characteristic of blanket bogs (Clark et al. 2010c, Gallego-Sala et al. 2010, Smart et al. 2010). We have identified southern and eastern regions (Northumbria, North York Moors, Peak District, South West) as being more exposed to projected changes in climate than cooler and wetter higher-altitude western and northern areas (Clark et al. 2010c, Gallego-Sala et al. 2010), with western areas more affected by acid deposition (Smart et al. 2010). However projections from models do not give clear results as to how this will affect carbon storage and must be treated with caution at this stage (Clark et al. 2010d). Some reduction of peatland carbon uptake seems likely, and in the long term there may be a reduction of the carbon store. Both observations and model studies indicate carbon loss is likely to be slower than it otherwise would be when continuous vegetation cover is be maintained.

There are key win-win management strategies for multiple services e.g. 'prevent erosion' and 're-vegetate eroded peatlands'. These measures may not halt the possible decline in peat carbon uptake, however failure to protect peat could lead to very large carbon losses, and thus a positive feedback to global warming. While losing only $12 \%$ of UK peatland carbon would be equivalent in climatic effect to the total annual UK emissions of greenhouse gases from the burning of fossil fuels, carbon loss due to management with or without additional loss due to climate change will take hundreds of years to deplete carbon stores. Ensuring a complete vegetation cover in the long-term is therefore worthwhile in terms of slowing peat and carbon loss. Expensive hydrological restoration may need further deliberation.

Within those areas we have identified as being most likely to experience climate stress, we can target management that will support retention of carbon, regardless of lack of certainty about rates of change. Long term monitoring of sites, and in particular of different management approaches (such as grip blocking), and their effects on carbon storage, wildfire (Albertson et 
al. 2010), bird populations (Pearce-Higgins 2010) and water quality and runoff are necessary to support understanding, future model development and decision making within the UK and elsewhere. Climate change and population growth could lead to increasing land pressure, especially if some upland areas become more suitable for agriculture. An ecosystem service approach (Cornell 2010, Maltby 2010) should contribute usefully to debate around what we want from our uplands and how we can manage these services sustainably in the future.

Acknowledgements. This research was funded by the Environment Agency (Science Project Sc070036) and the NERC Quantifying and Understanding the Earth System (QUEST) research programme. J.M.C. was also supported by a fellowship from the Grantham Institute for Climate Change, Imperial College; P.S. is a Royal Society-Wolfson Research Merit Award holder. The views expressed are those of the authors and do not necessarily represent the position of the funding organisations.

\section{LITERATURE CITED}

Albertson K, Aylen J, Cavan G, McMorrow J (2010) Climate change and the future occurrence of moorland wildfires in the Peak District of the UK. Clim Res 45:105-118

Billett MF, Deacon C, Palmer SM, Dawson JJC, Hope D (2006) Connecting organic carbon in streamwater and soils in a peatland catchment. J Geophys Res Biogeosciences 111, GO2010, doi:10.1029/2005JG000065

Billett MF, Garnett MH, Harvey F (2007) UK peatland streams release old carbon dioxide to the atmosphere and young dissolved organic carbon to rivers. Geophys Res Lett 34: L23401 doi:10.1029/2007GL031797

Billett MF, Charman DJ, Clark JM, Evans CD and others (2010) Carbon balance of UK peatlands: current state of knowledge and future research challenges. Clim Res 45: 13-29

Bonn A, Allott T, Hubacek K, Stewart J (2009a). Drivers of environmental change in Uplands. Routledge, Abingdon

Bonn A, Holden J, Parnell M, Worrall F and others (2009b). Ecosystem services of peat - Phase 1. Unpublished report to Dept. for Environment, Food and Rural Affairs, London. Project code: SP0572

Burt TP, Holden J (2010) Changing temperature and rainfall gradients in the British Uplands. Clim Res 45:57-70

Charman D (2002) Peatlands and environmental change. John Wiley, Chichester

> Clark JM, Bottrell SH, Evans CD, Monteith DT and others (2010a) The importance of the relationship between scale and process in understanding long-term DOC dynamics. Sci Total Environ doi:10.1016/j.scitotenv.2010.02.046

Clark JM, Orr HG, Freer J, House JI, Smith P, Freeman C (2010b) Assessment of projected changes in upland environments using simple climatic indices. Clim Res 45:87-104

- Clark JM, Gallego-Sala AV, Allott TEH, Chapman SJ and others (2010c) Assessing the vulnerability of blanket peat to climate change using an ensemble of statistical bioclimatic envelope models. Clim Res 45:131-150

Clark JM, Billett MF, Coyle M, Croft S and others (2010d) Model inter-comparison between statistical and dynamic model assessments of the long-term stability of blanket peat in Great Britain (1940-2099). Clim Res 45:227-248

Coll J, Gibb SW, Price MF, McClatchey J, Harrison J (2010) Developing site scale projections of climate change in the Scottish Highlands. Clim Res 45:71-85

Cornell S (2010) Valuing ecosystem benefits in a dynamic world. Clim Res 45:261-272

Dinsmore KJ, Billett MF, Skiba UM, Rees RM, Helfter C (2010) Role of the aquatic pathway in the carbon and greenhouse gas budgets of a peatland catchment. Glob Change Biol 16:2750-2762 doi:10.1111/j.1365-2486.2009.02119.x

> Evans CD, Monteith DT, Cooper DM (2005) Long-term increases in surface water dissolved organic carbon: observations, possible causes and environmental impacts. Environ Pollut 137:55-71

- Evans CD, Freeman C, Cork LG, Thomas DN and others (2007) Evidence against recent climate-induced destabilisation of soil carbon from ${ }^{14} \mathrm{C}$ analysis of riverine dissolved organic matter. Geophys Res Lett 34:L07407 doi:10.1029/ 2007GL029431

- Evans M, Lindsay J (2010) Impact of gully erosion on carbon sequestration in blanket peatlands. Clim Res 45:31-41

> Evans M, Warburton J, Yang J (2006) Sediment budgets for eroding blanket peat catchments: global and local implications of upland organic sediment budgets. Geomorphology 79:45-57

> Everard M, Colvin JD, Mander M, Dickens C, Chimbuya S (2009) Integrated catchment value systems. J Water Res Prot 3:174-187

- Freeman C, Evans CD, Monteith DT, Reynolds B, Fenner N (2001) Export of organic carbon from peat soils. Nature 412:785

Freeman C, Fenner N, Ostle NJ, Kang H and others (2004) Export of dissolved organic carbon from peatlands under elevated carbon dioxide levels. Nature 430:195-198

> Gallego-Sala AV, Clark JM, House JI, Orr HG and others (2010) Bioclimatic envelope model of climate change impacts on blanket peatland distribution in Great Britain. Clim Res 45:151-162

> Heinemeyer A, Croft S, Garnett MH, Gloor E, Holden J, Lomas MR, Ineson P (2010) The MILLENNIA peat cohort model: predicting past, present and future soil carbon budgets and fluxes under changing climates in peatlands. Clim Res 45:207-226

Holden J (2009) Upland hydrology. In: Bonn A, Allott T, Hubacek K, Stewart J (eds) Drivers of environmental change in uplands. Routledge London, p 113-134

$>$ Holden J, Shotbolt L, Bonn A, Burt TP and others (2007) Environmental change in moorland landscapes. Earth Sci Rev 82:75-100

House JI, Clark J, Gallego-Sala A, Orr HG (eds) (2010) Vulnerability of upland peatland services to climate change. Environment Agency Science Report SR070036

Hulme M, Jenkins GL, Lu X, Turnpenny JR and others (2002) Climate change scenarios for the United Kingdon: the UKCIP02 scientific report. Tyndall Centre for Climate Change Research, School of Environmental Sciences, University of East Anglia, Norwich

IPCC (Intergovernmental Panel on Climate Change) (2000) Special report on emissions scenarios (SRES). Cambridge University Press, Cambridge

Lohila A, Aurela M, Tuovinen JP, Laurila T (2004) Annual $\mathrm{CO}_{2}$ exchange of a peat field growing spring barley or perennial forage grass. J Geophys Res 109:D18116 doi: 10.1029/2004JD004715

Malby AR, Whyatt JD, Timmis R, Wilby RL, Orr HG (2007) Forcing of orographic rainfall and rainshadow processes 
by climate change: analysis and implications in the English Lake District. Hydrol Process 52:276-291

Maljanen M, Martikainen PJ, Walden J, Silvola J (2001) $\mathrm{CO}_{2}$ exchange in an organic field growing barley or grass in eastern Finland. Glob Change Biol 7:679-692

Maljanen M, Komulainen VM, Hytonen J, Martikainen P, Laine J (2004) Carbon dioxide, nitrous oxide and methane dynamics in boreal organic agricultural soils with different soil characteristics. Soil Biol Biochem 36:1801-1808

Maltby E (2010) Effects of climate change on the societal benefits of UK upland peat ecosystems: applying the ecosystem approach. Clim Res 45:249-259

Manley G (1952) Climate and the British scene. New Naturalist No 22, Collins, London

McMorrow JM, Lindley SJ, Aylen J, Cavan G, Albertson K, Boys D (2009) Moorland wildfire risk, visitors and climate change: patterns, prevention and policy. In: Bonn A, Allott T, Hubacek K, Stewart J (eds) Drivers of environmental change in Uplands. Routledge, London, p 404-431

Monteith DT, Stoddard JL, Evans CD, de Wit HA and others (2007) Dissolved organic carbon trends resulting from changes in atmospheric deposition chemistry. Nature 450: $537-540$

Moors for the Future (2007) Carbon flux from Peak District moorlands. Research Note No 12. www.moorsforthefuture. org.uk

Nykänen H, Alm J, Lang K, Silvola J, Martikainen PJ (1995) Emissions of $\mathrm{CH}_{4}, \mathrm{~N}_{2} \mathrm{O}$ and $\mathrm{CO}_{2}$ from a virgin fen and a fen drained for grassland in Finland. J Biogeogr 22: 351-357

Orr HG, Wilby RL, Hedger MM, Brown I (2008) Climate change in the uplands: a UK perspective on safeguarding regulatory ecosystem services. Clim Res 37:77-98

Palmer SM, Hope D, Billett MF, Dawson JJC, Bryant CL (2001) Sources of organic and inorganic carbon in a head- water stream: evidence from carbon isotope studies. Biogeochemistry 52:321-338

Pearce-Higgins JW (2010) Using diet to assess the sensitivity of northern and upland birds to climate change. Clim Res 45:119-130

> Pearson RG, Dawson TP (2003) Predicting the impacts of climate change on the distribution of species: Are bioclimate envelope models useful? Glob Ecol Biogeogr 12:361-371

> Smart SM, Henrys PA, Scott WA, Hall JR and others (2010) Impacts of pollution and climate change on ombrotrophic Sphagnum species in the UK: analysis of uncertainties in two empirical niche models. Clim Res 45:163-177

Smith J, Gottschalk P, Bellarby J, Chapman S and others (2010a) Estimating changes in Scottish soil carbon stocks using ECOSSE. I. Model description and uncertainties. Clim Res 45:179-192

Smith J, Gottschalk P, Bellarby J, Chapman S and others (2010b) Estimating changes in Scottish soil carbon stocks using ECOSSE. II. Application. Clim Res 45:193-205

> Ward SE, Bardgett RD, McNamara NP, Adamson JK, Ostle NJ (2007) Long-term consequences of grazing and burning on northern peatland carbon dynamics. Ecosystems 10: 1069-1083. doi:10.1007/s10021-007-9080-5

Wilson L, Wilson J, Holden J, Johnstone I, Armstrong A, Morris $M$ (2010) Recovery of water tables in Welsh blanket bog after drain blocking: discharge rates, time scales and the influence of local conditions. J Hydrol (Amst) 391:377-386

Worrall F, Evans MG, Bonn A, Reed MS, Chapman D, Holden J (2009) Can carbon offsetting pay for upland ecological restoration? Sci Total Environ 408:26-36

Yallop AR, Clutterbuck B, Thacker J (2010) Increases in humic dissolved organic carbon export from upland peat catchments: the role of temperature, declining sulphur deposition and changes in land management. Clim Res 45: 43-56 